\title{
Joubert syndrome with oculorenal defect
}

INSERM

\section{Source}

INSERM. (1999). Orphanet: an online rare disease and orphan drug data base. Joubert syndrome with oculorenal defect. ORPHA:2318

Joubert syndrome with oculorenal defect is a rare subtype of Joubert syndrome and related disorders (JSRD, see this term) characterized by the neurological features of JS associated with both renal and ocular disease. 